International Journal of English Literature and Social Sciences
Vol-6, Issue-5; Sep-Oct, 2021

Peer-Reviewed Journal

\title{
Equity in Online Learning Amidst Pandemic in the Philippines
}

\author{
Maria Angela S. Esteron
}

Graduate Studies of Education Management, Nueva Ecija University for Science and Technology, Philippines

Received: 05 Sep 2021; Received in revised form: 26 Sep 2021; Accepted: 06 Oct 2021; Available online: 12 Oct 2021

(C)2021 The Author(s). Published by Infogain Publication. This is an open access article under the CC BY license

(https://creativecommons.org/licenses/by/4.0/).

\begin{abstract}
Due to the COVID-19 pandemic, face-to-face learning engagement of students and the teachers in the school has been suspended. This pandemic has paved the way to the implementation of the different distance learning modalities as urgent response to ensure safety of the students and continuity of education. Equity in education means, granting educational opportunities to anyone on equal basis; disregarding of the nationality, gender, ideological differences or mental and physical disabilities. Thus, having equity in online learning is ensuring inclusive and equitable quality education and promote lifelong learning opportunities for all.

Online learning has merits and demerits. Online learning is efficient, affordable, and flexible. It can also suit various learning styles as a learning delivery modality. Online learning also has positive and negative implication to the values and ethics of the learners. Some of the positive implication to learners' values is having persistence, self-discipline, and respect while having online learning. On the other hand, there is also a negative implication to learners' values like online academic fraud. Equity in online learning in the Philippines is still in progress because not all learners can have a good internet connectivity, a device to use and technological literacy. It calls for all teachers to be trained in teaching online with equity issues part of the training. This paper strongly supports the need for online learning in the times of crisis, but suggests that it must done professionally and with equity.
\end{abstract}

Keywords - equity, online learning, pandemic, access, technology.

\section{INTRODUCTION}

Learners used to attend to classroom everyday as their traditional learning environment but pandemic has brought enormous changes in the lives of the people especially in education. As a result, education has changed dramatically, with the distinctive rise of e-learning, whereby teaching is undertaken remotely and on digital platforms. Different learning modalities has been used as alternative for faceto-face classes such as modular learning and blended learning and online learning.

Due to the COVID-19 pandemic, face-to-face learning engagement of students and the teachers in the school has been suspended. This pandemic has paved the way to the implementation of the different distance learning modalities as urgent response to ensure safety of the students and continuity of education. According to Quinones (2020), Distance Learning refers to a learning delivery modality, where learning takes place between the teacher and the learners who are geographically remote from each other during instruction. This modality has three types: Modular Distance Learning (MDL), Online Distance Learning (ODL), and TV/Radio-Based Instruction.

Quick transition to an online learning, the Department of Education crafted guidelines on learning activities, revised assessment measures, and set promotion policies. Consequently, the learning experiences of students varied at their own home. Students faces countless challenges with these change particularly poor internet connection, limited access to gadgets, and lack of study space at home. 
Further, lack of support or assistance from the family can be one of the challenges that makes learning more difficult in times of crisis. The Philippines is currently in the process of adapting to the new normal form of education.

Alberto et.al (2021) in the study, Barriers to Online Learning in the Time of COVID 19: A National Survey of Medical Students in the Philippines. In the Philippines, a low-middle-income country in Southeast Asia, classes in all levels were suspended in mid- March of 2020, after the government had put the country's largest island Luzon and other major cities under lockdown. Halfway into the second semester, schools had to cease all face-to-face learning activities. Medical students were removed from clinics, wards, intensive care units, and emergency departments. Local and international electives were cancelled. The national internship program was likewise suspended, and the licensure examinations postponed indefinitely. Forced to abruptly transition to an online curriculum, each school crafted its own guidelines on learning activities, revised assessment measures, and set promotion policies.

According to Horn \& Staker (2013), online learning, where instruction is delivered primarily over the internet, is leading the transformation of public education in the United States. Since online schools began in the mid-90s, thousands of programs have been created, ranging from small programs within a local school, to online schools, to state-wide programs, multistate, and international programs. All of these online learning programs can be categorized under the umbrella of distance education. In addition, a growing cadre of schools are transforming teaching and learning through blended learning. Horn and Staker define blended learning as “... any time a student learns, at least in part, at a supervised brick-and-mortar location away from home and, at least in part, through online delivery with some element of student control over time, place, path, and/or pace. The modality along each student's learning path within a course or subject are connected to provide an integrated learning experience"

On the other hand, based on Petrulis (2020), in a journal "Access and Equity in Online Learning," The sudden shift to online learning can deepen existing inequalities. The uneven distribution and access to technology combined with the implications of a global pandemic for different socio-economic and racial group's means that many students will be disproportionately affected by the shift to remote work. For instructors, this means that we need to think about logistical and technological concerns as inseparable from pedagogical ones. Considering all of the factors that may be affecting student performance also means curating an inclusive pedagogy that prioritizes equitable access to the learning environment.

Moreover, he added that inclusive pedagogy asks us to consider how we can help all students succeed. Facilitating inclusion in the physical classroom often means creating spaces where students feel valued and included, setting clear expectations, and making learning and assessment accessible to all students. Though the online shift can complicate these strategies, the principles remain the same. Adapted to online teaching contexts, inclusive teaching and learning requires transparency, accessibility, and flexibility.

A holistic approach to education -that addresses students' learning, social and emotional needs -is crucial, especially in times of crisis. School closures related to the current COVID-19 pandemic mean that students from diverse backgrounds who are more at risk of increased vulnerability are less likely to receive the support and extra services they need, and the gap between students that experience additional barriers and that do not might widen. Closures can also have considerable effects on students' sense of belonging to schools and their feelings of self-worth -these are key for inclusion in education. (OECD, 2020)

The current coronavirus (COVID-19) pandemic is having a profound impact, not only on people's health, but also on how they learn, work and live. Among the most important challenges created by COVID-19 is how to adapt a system of education built around physical schools. At its peak, more than 188 countries, encompassing around $91 \%$ of enrolled learners worldwide, closed their schools to try to contain the spread of the virus. School closures have a very real impact on all students, but especially on the most vulnerable ones who are more likely to face additional barriers.

Children and youth from low-income and singleparent families, ethnic minority and Indigenous backgrounds; with diverse gender, identities and sexual orientations; and those with special education needs suffer by being deprived of physical learning opportunities, social and emotional support available in schools and extra services such as school meals. They risk falling further behind and becoming isolated with school doors closed. These students are likely to lose the most in terms of educational outcomes and the support provided by schools if countries take insufficient measures to promote educational equity and inclusion. 


\section{REVIEW OF RELATED LITERATURE AND STUDIES}

"Technology can be a powerful tool for transforming learning. It can help affirm and advance relationships between educators and students, reinvent our approaches to learning and collaboration, shrink long-standing equity and accessibility gaps, and adapt learning experiences to meet the needs of all learners." (EdSurge, 2020)

Amid closures in schools across the country, online learning offers opportunities for culturally responsive instruction. This positions the learner's cultural identities at the core of the learning process and uses the learner's cultural knowledge, experiences, and frames of reference in order to help students be successful in the course and at the school. This gives the teacher a chance to make a personal connection with the students. As educators, it is necessary to be responsive to students' academic and social emotional needs. Content can be de-prioritized while building individual relationships with students to ensure their mental and physical health and safety are fine and each student feels welcomed and valued.

While we have seen many great strides in using technology to reinvent learning and collaboration, we have also seen many issues arise in providing access to all schools and students. Since technology has been around, a digital divide has existed. But this gap between those who have ready access to computers and the Internet, and those who do not either because of social or geographical barriers, but it has become much more apparent with the pandemic. (USA Today) The issue of equity has always been inherent in discussions of distance education, because the aim of distance education is usually to widen access to those unable to access conventional educational offerings. However, as online learning has grown, and has become more mainstream, particularly in terms of blended and hybrid learning, critics have quite reasonably raised questions about whether or not online learning actually increases inequities, particularly for those in poverty, in remote regions, or within specific socio-economic or ethnic groups. (Sator and Williams, 2020)

Sator and Williams (2020) also stated the factors in online learning which are relevant to equity issues. The three foundational underpinnings for pedagogy in online learning are equity mindedness, cultural affirmation, and social engagement. The following need to be considered for equity issues when considering or designing online learning such as access to materials, digital literacy, quality of instruction and resources, and pedagogical issues: 'equity mindedness', reflecting the cultural diversity of learners in course materials and design, use of universal design for enabling greater accessibility to materials and, intentional community building for social engagement.

Online learning can be defined as instruction delivered on a digital device that is intended to support learning. In the literature, several advantages of online learning have been highlighted: studying from anywhere, at any time; possibility of saving significant amounts of money; no commuting on crowded buses or local trains; flexibility to choose; and saving time. Online learning, thus becoming more and more important for education during the time of pandemic, offering the opportunity to remain in touch, even if remotely, with classmates and teachers and to follow lessons. The adoption of online learning in a situation of emergency represents a need, but it has also stimulated experts, policymakers, citizens, teachers and learners to search for new solutions. This is producing a shift from the concept of online learning to emergency remote teaching, which represents "a temporary shift of instructional delivery to an alternate delivery mode due to crisis circumstances."

As stated by UNESCO Director-General Audrey Azoulay: "We are entering uncharted territory and working with countries to find hi-tech, low-tech and no-tech solutions to assure the continuity of learning". For this reason, new challenges and opportunities at a social and technological level may emerge. It is an experience that enables us to reflect on the different approaches and lessons learned in different countries and additionally provides an opportunity to find new solutions. In fact, greater reflection on and study of social challenges related to the current pandemic and more generally to global crises are necessary.

Inclusive changes in education delivery through education investment and reforms at the governance level are necessary. This pandemic can be an opportunity and an exercise for emergency remote teaching to evaluate emerged challenges during emergencies and develop a coherent online education strategy for any other emergencies or natural disasters that can potentially happen in the future.

"Education systems around the world are facing an unprecedented challenge in the wake of massive school closures mandated as part of public health efforts to contain the spread of COVID-19. Governmental agencies are working with international organizations, private sector partners and civil society to deliver education remotely through a mix of technologies in order to ensure continuity of curriculum-based study and learning for all". (UNESCO on Distance Learning Solutions, 2020)

Furthermore, one of the aims of The Global Education 2030 Agenda of UNESCO is the quality education which 
aims to "ensure inclusive and equitable quality education and promote lifelong learning opportunities for all". In this context, more attention is necessary on how technology and learning can be integrated effectively, including the vital role of teachers, and the students' needs.

Yusuf (2020) suggests that institutions should provide more adequate e-learning platforms to increase access to the Internet and develop an interactive learning approach. Moreover, it is necessary to provide workshops or training for teachers and students to improve their technological and pedagogical competencies in online learning. The question of inclusion is central when we consider emergency remote teaching. Inclusion may have different characteristics across countries.

Thomas and Rogers (2020), starting from their experiences of online learning during the pandemic emergency, have observed that school-provided IT systems are frequently too expensive, cumbersome and quickly go out of date. They suggest moving to personal devices integrated into schools. Moreover, they recommend that policymakers incentivize and encourage companies to produce engaging and powerful educational games and learning environments. To ensure education will encourage children's engagement and curiosity.

Eder (2020), additionally suggests using television or radio for online learning in order to reach learners who lack access to the Internet, although this requires time to plan and programme content. Nevertheless, it is worth noting that different media like radio and television were also used in 2014 during the Ebola crisis. Furthermore, during the current crisis, some countries have used different modalities for online learning to avoid the problem of the digital divide.

Rose et.al (2007), in the study Access and Equity in Online Classes and Virtual Schools, Online equity must address the basic access issues - all students given access to online content. Virtual schools have, in large part, been designed to make content available to students who wouldn't otherwise be able to access that content. Virtual programs that focus on Advanced Placement courses are doing so because the program sponsors and creators recognize that not all segments of the student population have the same advantage when it comes to being accepted into competitive colleges. When we refer to online equity, we're not talking about the digital divide, though there are elements of the digital divide discussion in this view of online equity. The digital divide discussion initially focused on which students had access to computers in school, characterizing them as the haves and have-nots. As the numbers of computers became less an issue, the discussion shifted to the issue of access to the internet. The digital divide has now been refined to look at high-speed access to the internet.

Public school programs that take the position students must have their own appropriate technology to access educational programs are creating problems for themselves. It's incumbent on public schools are obligated to ensure that all students can take advantage of and benefit from the particular services and programs they provide.

Equity and equality have different legal definitions. If a school doesn't provide computer or internet access to any students in their online program, that treatment is considered equal. However, when only those students with personal computers and internet access at home are able to take advantage of the benefits and opportunities of the online program, the program is not considered equitable. It is also potential a legal issue if any of those students without computers and internet connectivity are protected by civil rights legislation.

Moreover, Rose et.al (2007) in the study, Access and Equity in Online Classes and Virtual Schools. Equitable access also means students with disabilities can't be denied access to online education because of their disability. It puts a burden on the program designers to ensure students with disabilities can easily access the online course content. Public schools have an obligation to provide access to the full benefit of education for all students. The civil rights and equity laws and policies prohibit students from being denied access to that education on the basis of economic status, race, sex, national origin, limited English language ability, or disability. There's an obligation to ensure that the program isn't having a negative differential impact on students because of the student's status.

The issues of access and equity have implications for every blended and online learning program. Access traditionally refers to both how and which students are allowed, by policy, practice, or technology, to enrol in a course or program. Equity is about the achievement of fairness in education, and in meeting the specific needs of specific students. (Blomeyer, 2005)

Public education is open to all, so any time there is a policy or practice that restricts admission to educational opportunity of a particular group of students, that policy is automatically suspect and usually illegal. Denying a group of students or even an individual student access to online courses or programs needs to be done very carefully. It is almost always impossible to justify a situation where a program or course offered through the public school system is unavailable because of a student's race, ethnicity, socioeconomic status, gender, or because the 
student is identified as having special needs or a disability. (Hanson, 2002)

In the wake of the COVID-19-propelled public health crisis, schools around the nation are turning to online learning for students. Technology presents a huge opportunity to engage students to continue their schooling. However, online education also brings a host of equity and access concerns, misperceptions around students' technology abilities, lack of access for students with no home internet access, and unique challenges for some student populations, including special education students and English learners.

According to Anderson and Perrin (2018), Pew Research Center analyzed 2015 U.S. Census Bureau 2018. In ensuring internet access for students, online education does not work when students cannot access it. Many students do not have access to the internet, laptops or tablets necessary for full participation in online courses or activities. There are $15 \%$ of households with school-aged children do not have a high-speed internet connection at home. One in four teens whose annual family income is less than $\$ 30,000$ does not have access to a home computer; and $17 \%$ of teens often or sometimes are unable to do their homework due to a lack of access to a computer or the internet. Many students do have access to the internet through their cell phones, but completing schoolwork through the phone is extremely difficult and hinders the learning process. While conference platforms like Zoom, Google Hangouts and online video streaming are the most interactive components of online education, they can burn through a phone data plan in one day, leaving many students to search for a Wi-Fi spot. Also, many students have no access to a printer.

The curriculum in an online course should be different from a traditional classroom to create a more personalized learning experience. Because online courses tend to require student-led pacing, consider expectations for student assignments, participation, and pacing to ensure active learning and engagement. Prepare curriculum to support learners of various reading levels and learning needs and provide supplementary materials for students who may struggle or need a different type of instruction. Thus, understand how to motivate individual learners and enhance student learning without the presence of visual cues (Hanover Research, 2015). Modify lessons, especially for students with special needs (DiPietro, et al., 2008). Better understand how online tools can apply to their own lessons and curriculum and conceptualize different ways to assess student learning and outcomes (Oliver, et al., 2010).

As what Costa et.al (2020) stated in the journal The Term Equity in Education: A Literature Review with
Scientific Mapping in Web of Science, today's society, marked by the heterogeneity of its citizens, requires concrete actions to achieve a truly inclusive education that offers equal opportunities for all students regardless of their ethnic background, socio-economic class, or gender. It is relevant to note that inclusive education has become an indispensable principle for dealing with students' diversity. Moreover, it must be equitable, example, a system where common goods are redistributed and additional resources are provided. In this case it makes it possible for all learners have a chance of success.

Although equity has become an essential axis in the education system we must consider the micro-political level that underlies the educational policies implemented: the neoliberal approach or the approach that considers equity as part of social justice. In any case, equity in the field of education should contribute to equal opportunities in access to studies regardless of gender, social origin, or ethnicity. Equity must promote academic results and quality, so that students can access higher education and thus break the inequality gap. Therefore, it is essential to promote compensatory educational policies such as schooling, resources, or scholarships and study aids and to develop organizational and cultural aspects in educational centers to encourage leadership practices. The interest in creating a more equitable educational system is evident.

Pedro, J.S. et al. (2020) in the journal, The Term Equity in Education: A Literature Review with Scientific Mapping in Web of Science, as digital learning reshapes K-12 education, educators, researchers, and developers have an unprecedented opportunity to reshape the education system themselves on the basis of a desire to create environments that are meaningful and equitable for all learners. To support these changes, various groups must work together to fully understand and design environments that consider variability and the environment that surrounds each learner. If online learning is the primary driver of a student's learning experience, considerations should be taken to support various domains, including academic, social, occupational, and life skills.

As noted, self-regulation is a key component to success in online courses. Therefore, non-self-regulated students tended to demonstrate academic procrastination, increased disorganization, and used less cognitive and metacognitive strategies to accomplish their learning goals (You \& Kang, 2014). Online course construction is as diverse as traditional classroom settings. Developing and teaching an online course that benefits students and yields positive learning outcomes is a complex undertaking. Attempting to recreate the traditional classroom in an online setting may not necessarily be the wisest course of action. 
Thomson, (2010, p. 703) advises online course creators "to capitalize on the benefits that the online environment can offer" and "to minimize the challenges specific to the environment." Courses should be well organized from the very start, providing the students with detailed instructions and expectations. Instructors should anticipate areas of potential misunderstanding and dismiss unclear directives prior to the start of the course. Misunderstandings can be minimized through a very detailed syllabus, course calendar, useful links, and course information that is chunked into digestible pieces.

Communication is notably one of the most crucial elements to an effective online course. Lehmann (2004, p. 9) states "communication is what separates true online learning from Web-based tutorials". Interaction and communication have been identified as key factors in the success of an online course, leading to enhanced student satisfaction and motivation. Interaction can take place in three central areas, interaction between the learner and the instructor, the learner and other learners, and the learner and the content. Interaction between the learner and the content is the most common type of interaction that occurs in online settings, through lectures and readings. Students to work collaboratively and cooperatively with other learners and/or the instructor in live debates, reflective journal entries, peer reviews, discussion boards, and video or audio teleconferencing (Savenye, 2005).

Many instructors spoke to the benefit of the individualized atmosphere of the online course and how to best capitalize on the one-to-one correspondence. Differentiating instruction in a traditional classroom can be very difficult due to the simultaneous interaction that an instructor must have with the students, "by contrast addressing individual needs of each student is easier to do with online students, since the nature of the system is more geared to individuals" (Thomson, 2010, p. 34).

Responding to students promptly is yet another important aspect of communication. Instructors and students alike expressed the importance of prompt and supportive feedback when working to "establish a rapport of trust and level of comfort" (Thomson, 2010). The more personal one-to-one emails were found to be useful when used in conjunction with mass class emails to target reoccurring questions, interact with the quieter students, and to build "a sense of the course as a dynamic shared enterprise" (Thomson, 2010, p. 704).

Overall, "successful students tend to have stronger beliefs they will succeed, higher self-responsibility, higher self-organization skills, and better technology skills and access" (Savenye, 2005, p. 2). Understanding learning styles and self-behavior is pertinent to determining ones success in the undertaking of an online learning. Some online learners experience a learning curve when first becoming acclimated with asking questions in various forums, instead of in a traditional face-to-face, classroom setting (Thomson, 2010).

It essential to recognize the diversity amongst gifted students in their interests, learning styles, and personalities, while simultaneously working to maximize on the characteristics of this group of learners (Thomson, 2010).

Gifted students could benefit greatly from an online learning environment which provides for more opportunities in areas of interest to the student and provided at a pace that is on track with their rate of learning. Expanding access to students is one asset of online learning. "Offering one or two online courses could benefit a specific segment of students identified as gifted and talented," (Chaney, 2001, p. 28) ultimately providing more opportunities in the competitive realm of education.

In terms of learners with disabilities, online learning has the capacity to break down barriers that have restricted individuals from an equitable education in the past. In order to establish a learning environment that is conducive for all participants, the students' needs must be put first to establish courses that are accessible for all learners (Oswald \& Meloncon, 2014).

The greater accessibility of education in terms of online courses is paving a path for more equal opportunities for students who do not fit the mold for the traditional classroom setting. As Chaika (1999) states, "distance education finally brings democracy to education" and it provides "an equal opportunity to content curriculum and to people with many perspectives... students who learn with each other with learn from each other. Distance education breaks down the barrier of location, "the single biggest factor influencing the quality of education". The demand for equity in education is a powerful reminder of the need for accessible online distance learning that extends opportunities beyond school district lines.

Oswald and Meloncon (2014), reported on a two studies conducted in 2010 by the Conference on College Composition and Communication (CCCC) Committee for Best Practice in Online Writing Instruction (OWI). One study focused on instructors who taught fully online courses, while the second study looked at instructors who taught hybrid courses. The data highlighted a discrepancy in accessibility and students with disabilities enrolment in the instructors' courses. The report revealed that 54 percent of instructors stated that their course was not accessible. Instructors admitted that they lacked knowledge, experience, and resources to meet the 
identified needs of the students. One instructor voiced their concerns on the lack of resources, time, and personnel to adequately accommodate students. "Designed correctly, distance education options create learning opportunities for everyone. Designed poorly, they erect barriers to equal participation in academics and careers" (Oswal \& Meloncon, 2014, p. 294). Accessibility has a profound effect on student engagement and academic performance, therefore greatly impacting the success of the learner.

\section{MERITS AND DEMERITS OF ONLINE LEARNING}

As with most teaching methods, online learning also has its own set of positives and negatives. Decoding and understanding these positives and negatives will help schools in creating strategies for more efficient delivery of the lessons, ensuring an uninterrupted learning journey for the students.

The new normal in education is the increased use of online learning tools. The COVID-19 pandemic has triggered new ways of learning. The new normal now is a transformed concept of education with online learning at the core of this transformation. Today, digital learning has emerged as a necessary resource for students and schools all over the world.

\section{Merits of Online Learning}

\subsection{Efficiency}

Online learning offers teachers an efficient way to deliver lessons to students. Online learning has a number of tools such as videos, PDFs, podcasts, and teachers can use all these tools as part of their lesson plans. By extending the lesson plan beyond traditional textbooks to include online resources, teachers are able to become more efficient educators.

\subsection{Flexibility}

Online learning allows learners to access anytime and anywhere. Another advantage of online learning is that it allows students to attend classes from any location of their choice. It also allows schools to reach out to a more extensive network of students, instead of being restricted by geographical boundaries. Additionally, online lectures can be recorded, archived, and shared for future reference. This allows students to access the learning material at a time of their comfort. Thus, online learning offers students the accessibility of time and place in education.

\subsection{Affordability}

Another advantage of online learning is reduced financial costs. Online education is far more affordable as compared to physical learning. This is because online learning eliminates the cost points of student transportation, student meals, and most importantly, real estate. Additionally, all the course or study materials are available online, thus creating a paperless learning environment which is more affordable, while also being beneficial to the environment.

\subsection{Improved Student Attendance}

Since online classes can be taken from home or location of choice, there are fewer chances of students missing out on lessons.

\subsection{Suits a Variety of Learning Styles}

Every student has a different a different learning style. Some students are visual learners, while some students prefer to learn through audio. The online learning system, with its range of options and resources, can be personalized in many ways. It is the best way to create a perfect learning environment suited to the needs of each student.

\section{Demerits of Online Learning}

\subsection{Inability to Focus on Screens}

One of the biggest challenges of online learning to some students, is the struggle with focusing on the screen for long periods of time. With online learning, there is also a greater chance for students to be easily distracted by social media.

\subsection{Technology Issues}

Another key challenge of online classes is internet connectivity. While internet connection has grown over the past few years, in smaller cities and towns especially in the Philippines, a consistent connection with decent speed is a problem. Without a consistent internet connection for students or teachers, there can be a lack of continuity in learning for the child. This is detrimental to the education process.

\subsection{Sense of Isolation}

Students can learn a lot from being in the company of their peers. However, in an online class, there are minimal physical interactions between students and teachers. This often results in a sense of isolation for the students. In this situation, it is vital that the school allow for other forms of 
communication between the students, peers, and teachers. This can include online messages, emails and video conferencing that will allow for face-to-face interaction and reduce the sense of isolation.

\subsection{Teacher Training}

Online learning requires teachers to have a basic understanding of using digital forms of learning. However, this is not the case always. Very often, teachers have a very basic understanding of technology. Sometimes, they don't even have the necessary resources and tools to conducts online classes. Thus, it is important for schools to invest in training teachers with the latest technology updates so that they can conduct their online classes seamlessly.

\subsection{Manage Screen Time}

Many parents are concerned about the health hazards of having their children spend so many hours staring at a screen. This increase in screen time is one of the biggest concerns and disadvantages of online learning. Sometimes students also develop bad posture and other physical problems due to staying hunched in front of a screen.

\section{Learner's Experiences of Online Learning}

\subsection{Social Isolation}

While primarily a place of education, school is also the center of many teens' social lives. School offers teenagers and young adults an opportunity to connect with their peers. It's an opportunity for them to socialize and express themselves. However, with schools and colleges moving to virtual formats, teens may feel lonely, unmotivated, or discouraged without regular social interaction. Numerous studies have shown social isolation can cause higher rates of negative outcomes for the mental and physical health of individuals. Other studies have found that face-to-face interactions can help reduce depression and anxiety. Less social interaction may increase feelings of social anxiety and pressures.

\subsection{Increased Stress \& Anxiety}

Alongside the lack of social interaction, online class structure can affect teens and adolescents in a number of ways. They may feel heightened anxiety about keeping up to date with their school work. Other teens may experience difficulty concentrating or staying focused while at home. For some adolescents and young adults, being in front of others on video can lead to its own anxieties. Students may find it difficult to receive the extra education support they need to succeed

\subsection{Virtual Learning Fatigue}

Spending a significant amount of time online can fatigue both students and their teachers. Sometimes, this impact is referred to as "Zoom fatigue." Part of the reason a day full of video interactions is so mentally draining is because our brains are unable to process information in the way it's accustomed to. When we have in-person interactions, there are a number of non-verbal cues our brains process. These cues include: Tone and pitch of voice, Facial expressions, Eye contact, and body language. When it's difficult or impossible to pick-up on these cues, our brain must work harder to interpret the information that it's receiving. On its own, this can cause extra mental fatigue. When this is coupled with the constant selfawareness of being on-camera in front of others, stress levels can easily begin to rise.

Based on the study, Barriers to Online Learning in the Time of COVID-19: A National Survey of Students in the Philippines, the pandemic had also caused psychological stress among the students, making it difficult for them to focus on studying. They expressed feelings of anxiety, burnout, loneliness, homesickness, grief, and hopelessness. The students worried about online assessments, future plans in medical school, possible delays in training, and safety of their families from COVID-19. Overall, $86 \%$ of the students reported experiencing some degree of mental health difficulty. Similarly high rates have been reported among medical students in Turkey, Japan, and Australia, and their concerns mirrored that of Filipino students. We noted that difficulty adjusting learning styles and mental health concerns were more common among female and non- binary respondents, those in the first 2 years of medical school, and those with a lower academic standing. This may partly account for observed variances in selfassessment of capacity for online learning. A large study among medical students in Japan recommended initiation of mental wellness programs that targeted enhancing selfesteem and self-efficacy, with focus on resilience training. Living in urban areas, economic stability, and living with parents have been shown to be protective factors against anxiety among students.

It was evident that more time spent at home did not necessarily equate to more time for academic work. There were students who could not concentrate because they were constantly exposed to conflict among family members. Even in the absence of domestic dispute, some found it hard to turn down conversations with parents or siblings. Filipino families are characterized by cohesiveness and reciprocity, and the most educated members are often expected to act as caregivers or household heads. In the current health crisis, many medical students had been relegated to this role. They took care of 
sick relatives, were in charge of buying food and supplies, or had to work for extra income. Moreover, although the learning environment may be virtual, physical space remained vital. Having a quiet study area, with the same comfort provided by a classroom or library, was a privilege not available to all. Medical students doubted the readiness of their schools to transition to online learning. They cited lack of guidelines, unfair policies, and haphazard class schedules, low quality of teaching materials, ineffective teaching strategies, and excessive class requirements.

Ensuring that students' social and emotional needs are being met and that the most vulnerable continue to receive extra services are challenges for governments and schools. During school closures, various countries have attempted to respond to the well-being needs of different vulnerable student groups (OECD, 2020). Students' sense of belonging to the school community may be lost unless they can keep in touch for learning, but also social activities, such as virtual games and reading buddies, via online resources like Zoom. The lack of social contact can be particularly impactful for vulnerable students: those with broken families, abusive families, in foster care, suffering from food insecurity or lacking housing. many LGBTQI+ students may experience exclusion and even verbal or physical violence at home. Transgender students lacking family or community support may struggle to access hormones needed and emotional or psychological support, which can have a worrying impact on their education. When providing such services, it is also important to pay increased attention to the gender dimension of the current crisis. Girls experience additional risks compared to boys during school closures, which span from an increased burden in domestic duties, mental health disparities and lack of access to sexual and reproductive health care, to greater risk of gender-based violence, including sexual assault. All these factors may impact girls' well-being differently than for boys.

Clark et.al (2020) from the study, The Covid-19 Pandemic and Violence against Women in Asia and the Pacific. Four times as many cases of online sex abuse against children were reported from March 2020 to May 2020 as compared to the same time frame in 2019. There are three main avenues along which the pandemic fosters violence: (1) increased exposure to perpetrators, (2) triggering environments for abusers and (3) limited or overrun support services. Incidents of intimate partner violence and digital violence are particularly likely to rise during lockdowns and remote work and school.

\section{IMPLICATIONS OF ONLINE LEARNING TO ETHICS AND VALUES OF STUDENTS}

Online Learning require just as much, if not more, time and energy as traditional classroom courses. Online learning have a positive and negative implication to values and ethics of the learners. Ethics in education means, granting educational opportunities to anyone on equal basis; disregarding of the nationality, gender, ideological differences or mental and physical disabilities. Through this perspective, online learning environments have an important potential in teaching and learning process. Considering the number and diversity of students in Online Learning environments, policies balancing different expectations and studying how the participants perceive ethics in online learning environments are important. During online courses, like in the face-to-face classes; students have to show respect to their instructors and classmates. Taking ethical principles into consideration in e-Learning leads to good relationship with others.

Code of Ethics for online communication lists the general moral laws as (1) contributing to society and human well-being (2) avoiding harm to others (3) being honest and trustworthy (4) being fair and taking action not to discriminate (5) honoring the property rights such as copyrights and patents (6) giving proper credit for intellectual property (7) respecting the privacy of others (8) honoring confidentiality (9) specific professional responsibilities (10) improving public understanding of computing and its consequences (11) accessing the computing and communication resources only when authorized to do so (12) articulating and supporting policies that protect the dignity of users and others affected by a computing system (Lengel, 2020).

Learners can acquire moral values and etiquette in Online Learning. Respect is one of the moral value that learners can acquire in online learning. Being polite when greeting, answering directly and without sarcasm, accepting others' opinions and beliefs, turning off microphones when necessary are some of the manifestations of respect in an online learning environment. Use of appropriate style and language when communicating. When communicating with teachers and other staff, students should write in full, grammatically correct sentences and with a respectful tone. Treat everyone with respect and courtesy.

Another moral value that can be learned in online learning is the value of persistence. Learners can become persistent in online learning. Persistence is perhaps the biggest key to success in online learning. Students who succeed are those who are willing to tolerate technical problems, seek help when needed, work daily on every 
class, and persist through challenges. Persistence can be achieved when keep on trying on how to learn lessons independently.

Self-discipline can also be acquired in online learning because learners should become organize, self-motivated and independent, and can manage time. Staying organized is essential for success in online courses. Because students don't have face-to-face interaction with teachers or peers, it's the responsibility of the individual student to stay organized and up to date with their course load. Furthermore, successful teachers and students know that staying motivated throughout their education program ensures that they get the most out of their learning. Staying motivated also means that successful students minimize the distractions around them. Online students need to have time management skills. Some students may set out a certain amount of time per day to spend on each subject. Others will use their organization skills to set up daily calendars and due dates for homework assignments in one handy location. By managing their time using some of the methods above, successful students are also able to engage in meaningful learning because they're preparing effectively for homework assignments and assessments.

There are also negative implications of Online learning to ethics and values of learners. It is said that one's dependency on the internet may cause them to ignore moral values and commit dishonorable acts. These findings are consistent with findings of studies by Young (1998), Kuss \& Griffiths (2012), and Dewi \&Trikusumaadi (2016), which conclude that addiction to the internet has adverse impacts on its users' personality and character. It was described early patterns of inappropriate behavior in e-learning. He identified the following categories of academic fraud in the e-learning environment: inappropriate assistance on examinations, misuse of sources on papers and projects, writing assistance and other inappropriate tutoring, misrepresentation in the collection and reporting of data, improper use of academic resources, disrespecting the work of others, lack of protection for human subjects in research, breaches of computer ethics, lack of adherence to copyright and copy-protection, providing inappropriate assistance to others and lack of adherence to academic regulations. The negative impacts of internet addiction will get stronger when value internalization is weak.

The negative impacts of internet on moral values may occur more extensively on other moral values. To eliminate the impacts of internet on the deterioration of moral values, preventive measures must be taken to prevent massive moral degradation. It is the responsibility of all parties for safeguarding the younger generations from moral hazards. Equity and access are important issues in online education. The virtual school community has a responsibility to ensure that the programs are accessible and the educational opportunities are equitable. Virtual education programs need to pay attention to these issues to be sure to have the greatest benefit to the largest number of students.

Virtual education programs can become hands-on on equity and access issues by collecting and analyzing student demographic data, then use that data to make program modifications where needed. Developing policies and procedures that require and ensure all courses and educational materials be broadly accessible. Developing special needs policies that explain the program responsibilities for service to special needs students. Creating and publicizing a non-discrimination policy.

It is important that all school employees have a good understanding of the online programs, and also understand their responsibilities related to student advice and guidance. There is ample research on how unintentional biases and stereotypes exist, and how they can color recommendations about students' potential for success and about course selection. And, if there is a feeling on the part of certain staff that blended or online education is not right for a particular group of students, and they make recommendations that result in a disproportion of students based on race, ethnicity, socio-economics, gender, or disability, there is potential for problems.

The key to providing equitable distance learning opportunities for all students is to recognize what this looks like for each student's unique situation. This transition from "all children" to "each child" is probably a heavier lift than the shift to distance learning. But by recognizing equity as an overarching aspect of every decision school system leaders are making as part of this transition, valuable lessons will be learned that will help schools serve students more effectively in this new distance learning environment.

Online learning curriculum needs to be planned out ahead of time, with syllabus, assignments, rubrics, examples of work, and resources posted on the course site ahead of time so that students can make the most of the flexibility of online course to work ahead as needed. Based form different studies, online learning has negative and positive views and effects to student's learning. In online learning, students study at home at their own pace, with the use of technologies. Some of the barriers to online learning can be bad internet connection, lack of motivation and devices. Home is different environment from school so the students might lose their concentration of doing their task. Self- discipline and self-regulation are necessary in online learning for students take the responsibility for 
their own learning because in online learning, students need to be much more self- motivated and self- directed as they cannot expect the teacher to monitor if and when they are doing the work.

This paper strongly supports the need for online learning in the times of crisis, but suggests that it must done professionally and with equity. It calls for all teachers to be trained in teaching online with equity issues part of the training. It is a call for instructors and course designers to not only know and understand the diversity of their students, but to reflect this within the design of their courses. Teachers and course designers should understand effective course development and design so students have a heightened chance for success.

\section{CONCLUSION}

During the coronavirus crisis, Philippines is one of the many countries that has been using digital online learning as mode of learning at the comfort of their own home. Vulnerable students might however have little access to such tools and require further attention and support. To respond to the challenges, government must have develop specific and innovative policy initiatives such as providing equitable and inclusive access to digital learning resources and good learning conditions, ensuring that socioemotional needs are being met, offering equitable support to students at risk of violence at home. Ensure social development of students. Support students whose parents have limited command of the language of instruction, address emotional needs of students, support education of students with special needs, ensure well-being of students, support education of underprivileged students, and the continuity of the academic learning of students. Thus, having equity in online learning is ensuring inclusive and equitable quality education and promote lifelong learning opportunities for all.

Online learning has merits and demerits. Online learning is efficient, affordable, and flexible. I can also suit various learning styles as a learning delivery modality. Aside from that, online learning also has positive and negative implication to the values and ethics of the learners. Some of the positive implication to learners' values is having persistence, self-discipline, and respect while having online learning. On the other hand there is also a negative implication to learners' values like online academic fraud. Equity in online learning in the Philippines is still in progress because not all learners can have a good internet connectivity, a device to use and technological literacy. However, few schools already adapted online learning as mode of learning. The following are recommendations:
1. Reliable network infrastructure needs to be developed. Teachers, students and parents must have internet connectivity that allows them to be able to take lessons remotely even when they are at remote areas. In fact, the results of the online discussion forum underlined that the intensive use of networks during the pandemic crisis has produced connection failures in several countries, especially Philippines.

2. Distribution of free electronic devices and learning material. Distributing free electronic devices and providing internet connection to disadvantaged and vulnerable students. More affordable devices must be provided. Devices such as tablets or computers to be connected should be less expensive and governments should give assistance to household's incentives to buy them. All the involved students, parents and teachers must have suitable devices to follow a lesson remotely in the most comfortable way. This issue was underlined by the experts, in particular for families with more than one child. It can help individuals, educational institutions and education systems to better adapt for life and work in an age of rapid digital change.

3. Systematic training initiatives should be provided to improve teachers' and learners' technological skills in relation to new emerging models and approaches encouraging the effective use of online learning. Ensuring support to and by teachers, providing resources for teachers by making online resources available and designing training to support teachers in teaching diverse groups of students online; Support for teachers' socioemotional well-being and organising for and/or developing guidelines to set standards on how to best support teachers' well-being during school closures so that they are in turn able to support vulnerable students' wellbeing. Teachers' initiatives and networks to support the learning and the inclusion of the most vulnerable

4. A clear and consistent plan should be developed, providing structured and planned educational material such content, methodologies and common goals, and more adequate e-learning platforms by using interactive suitable digital learning resources such as video, animations, quizzes and games to maintain students' attention. Provide different choice of technological platforms where learners can be motivated and enjoy participating in the class. Many platforms could be developed and made available, encouraging students' participation in content creation and their inclusion in the learning process. More inclusive tools, platforms and devices considering different web content accessibility guidelines need to be developed in order to make digital learning resources accessible to a wider range of people with disabilities. 
5. Parental engagement is necessary. Encouraging such engagement to ensure support and good learning conditions to students, with a focus on vulnerable groups. Providing equitable and inclusive access to good learning conditions. Keeping study areas safe and quiet spaces to study can have an effect to effective online learning. Parents' support, time, attention and guidance are necessary in the success of online learning in times of pandemic.

\section{REFERENCES}

[1] Anderson, M., \& Perrin, A. (October 26, 2018.) "Nearly one-in-five teens can't always finish their homework because of the digital divide," Pew Research Center. Retrieved from: https://www.idra.org/services/ensuringequity-in-online-learning-considerations-in-response-tocovid-19s-impact-on-schooling/

[2] Blomeyer, R. L., \& Dawson, M. (2005). Policy context of virtual schools. In Z. L. Berge \& T. Clark (Eds.), Virtual schools: Planning for success (pp. 61-76). New York: Teachers College Press.

[3] Blomeyer, R. L., \& Dawson, M. (2005). Policy context of virtual schools. In Z. L. Berge \& T. Clark

[4] Bowen, W.G., Chingos, M.M., Lack, K. A., \& Nygren, T.I. (2014). Interactive Learning Online at Public Universities: Evidence from a Six-Campus Randomized Trial. Journal Of Policy Analysis \& Management, 33(1), 94-111. doi: 10.1002/pam 2178

[5] Cai, C. Clark. L, Oguzhan, C. Sharmin, F. and Berliat, R. 2020. The Covid-19 Pandemic and Violence Against Women in Asia and the Pacific. Retrieved from: https://www.unescap.org/sites/default/files/20201123_SDD _Policy_Paper\%20Covid-19-VAW.pdf

[6] Chaika, G. 1999. Virtual high schools: The high schools of the future? Retrieved February 16, 2015, from http://www.educationworld.com/a_curr/curr119.shtml

[7] Chaney E. G. (2001). Web-based instruction in a Rural High School: A Collaborative Inquiry into Its Effectiveness and Desirability. NASSP Bulletin, 85(628), 20-35.

[8] Donlevy, J. (2003). Teachers, technology and training: Online learning in virtual high school. International Journal of Instructional Media, 30(2), 117-121. Retrieved from

http://search.proquest.com/docview/204262673?accountid= 27700

[9] DiPietro, M., Ferdig, R.E., Black, E.W., \& Preston, M. (2008). "Best Practices in Teaching K-12 Online: Lessons Learned from Michigan Virtual School Teachers," Journal of Interactive Learning, 7(1).

[10] Eder, R.B. The remoteness of remote learning. J. Interdiscip. Stud. Educ. 2020, 9, 168-171. [CrossRef]

[11] EdSurge article - The 3 Biggest Remote Teaching Concerns We Need to Solve Now https://www.digitallearningcollab.com/equity-and-access

[12] (Eds.), Virtual schools: Planning for success (pp. 61-76). New York: Teachers College Press.
[13] Hanover Research. (2015). Best Practices in K-12 Online and Hybrid Courses. Hanover Research.

[14] Hanson, K. E-Learning and Gender: (2002) Supporting women's learning Gender and Diversities Institute at EDC, AWID Conference, Guadalajara, Mexico.

[15] Hanson, K. E-Learning and Gender: (2002) Supporting women's learning Gender and Diversities Institute at EDC, AWID Conference, Guadalajara, Mexico.

[16] High Focus Centers Retrieved from: https://highfocuscenters.pyramidhealthcarepa.com/theeffects-of-online-learning-on-a-teens-mental-health/

[17] Institute of Educational Sciences. National Center for Educational Statistics. Retrieved December 8, 2014, from http://nces.ed.gov/fastfacts/display.asp?id=79

[18] Kirtman, L. (2009). Online versus in-class courses: An examination of differences in learning outcomes. Issues in Teacher Education, 18(2), 103-116. Retrieved from http://search.proquest.com/docview/233320851 ?accountid= 27700.

[19] Lehmann, K. (2004). How to be a great online teacher. Lanham, Md: Scarecrow Education.

[20] Matuga, J. M. (2009). Self-regulation, goal orientation, and academic achievement of secondary students in online university courses. Journal of Educational Technology \& Society, 12(3), 4-n/a. Retrieved from http://search.proquest.com/docview/1287037464?accountid $=27700$

[21] National Association for Gifted Children | Supporting the needs of high potential learners. (n.d.). Retrieved February 17, 2015, from http://www.nagc.org/

[22] OECD (2020), "OECD Policy Responses to Coronavirus (COVID-19): Combatting COVID-19's effect on children”, Tackling Coronavirus (Covid-19): Contributing to a Global Effort, OECD. Retrieved from: http://www.oecd.org/education/ceri/Spotlight-21Coronavirus-special-edition-Back-to-school.pdf

[23] OECD (2020), "Learning remotely when schools close: How well are students and schools prepared? Insight from PISA", Tackling Coronavirus (COVID-19): Contributing to a Global Effort, OECD. Retrieved from: http://www.oecd.org/education/ceri/Spotlight-21Coronavirus-special-edition-Back-to-school.pdf.

[24] Oliver, K., Kellogg, S., Townsend, L., \& Brady, K. (2010). "Needs of Elementary and Middle School Teachers Developing Online Courses for a Virtual School," Distance Education, 31(1), 55-75

[25] Oswal, S. K., \& Meloncon, L. (2014). Paying Attention to Accessibility When Designing Online Courses in Technical and Professional Communication. Journal of Business and Technical Communication, 28(3) 271-300. Doi: 1050651914524780.

[26] (PDF) Effect of Internet Drawbacks on Moral and Social Values of Users in Education https://www.researchgate.net/publication/267941714_Effec t_of_Internet_Drawbacks_on_Moral_and_Social_Values_o f_Users_in_Education

[27] Pedro Jurado de los Santos, Antonio-José MorenoGuerrero, José-Antonio Marín-Marín, and Rebeca Soler 
Costa $^{3}$ The Term Equity in Education: A Literature Review with Scientific Mapping in Web of Science https://www.ncbi.nlm.nih.gov/pmc/articles/PMC7277144/

[28] Roblyer, M. D., \& Marshall, J. C. (2002-2003). Predicting success of virtual high school distance learners: Preliminary results from an educational success prediction instrument. Journal of Research on Technology in Education, 35(2), 241-255.

[29] Rose, R, M., \& Smith, A. (2007) What Works in Online Discussion. In Cavanaugh, C. \& Blomeyer, R. (eds.) What Works in K-12 Online Learning (pp.tbd). Eugene, OR: International Society for Technology in Education

[30] Ryabov, I. (2012). The effect of time online on grades in online sociology courses. Journal of Online Learning and Teaching, $8(1), \quad 13 . \quad$ Retrieved from http://search.proquest.com/docview/1499783903?accountid $=27700$

[31] Rovai, A. P., Wighting, M. J., \& Liu, J. (2005). SCHOOL CLIMATE: Sense of classroom and school communities in online and on-campus higher education courses. Quarterly Review of Distance Education, 6(4), 361-374. Retrieved from

http://search.proquest.com/docview/231071527?accountid= 27700

[32] Sator, A. and Williams, H. (2020) Removing Barriers to Online Learning Through a Teacing and Learning Lens Victoria BC: BCcampus/ABLE Research Consultants

[33] Rose, R, M., \& Smith, A. (2007) What Works in Online Discussion. In Cavanaugh, C. \& Blomeyer, R. (eds.) What Works in K-12 Online Learning (pp.tbd). Eugene, OR: International Society for Technology in Education

[34] Reviewing online learning facing the Covid-19 outbreak. J. Talent Dev. Excell. 2020, 12, 385-392.

[35] Ryabov, I. (2012). The effect of time online on grades in online sociology courses. Journal of Online Learning and Teaching, $8(1), \quad 13 . \quad$ Retrieved from http://search.proquest.com/docview/1499783903?accountid $=27700$

[36] Rovai, A. P., Wighting, M. J., \& Liu, J. (2005). SCHOOL CLIMATE: Sense of classroom and school communities in online and on-campus higher education courses. Quarterly Review of Distance Education, 6(4), 361-374. Retrieved from

$\mathrm{http} / / /$ search.proquest.com/docview/231071527?accountid= 27700

[37] Sator, A. and Williams, H. (2020) Removing Barriers to Online Learning Through a Teacing and Learning Lens Victoria BC: BCcampus/

[38] Thomas, M.S.; Rogers, C. Education, the science of learning, and the COVID-19 crisis. Prospects 2020, 1. [CrossRef] [PubMed]

[39] Thomson, L. D. (2010). Beyond the Classroom Walls: Teachers' and Students' Perspectives on How Online Learning Can Meet the Needs of Gifted Students. Journal of Advanced Academics, 21(4), 662-712. http://joa.sagepub.com.pluma.sjfc.edu/content/21/4/662.full .pdf+html
[40] U.S. Department of Education, Office of Planning, Evaluation, and Policy Development, Evaluation of Evidence-Based Practices in Online Learning: A MetaAnalysis and Review of Online Learning Studies, Washington, $\quad$ D.C., 2010. https://www2.ed.gov/rschstat/eval/tech/evidence-basedpractices/finalreport.pdf.

[41] UNESCO. COVID-19 Educational Disruption and Response. 2020.2 Available online: https://en.unesco.org/covid19 (accessed on 30 July 2020).

[42] UNESCO. Distance Learning Solutions. 2020. Available online: https://en.unesco.org/covid19/educationresponse/ solutions (accessed on 7 September 2020).

[43] USA Today article - Coronavirus for kids without internet: Quarantined worksheets, learning in parking lots https://www.digitallearningcollab.com/equity-and-access

[44] Verawardina, U. Asnur, L. Lubis, A.L. Hendriyani, Y. Ramadhani, D. Dewi, I.P. Sriwahyuni, T. Distance Education Courses for Public Elementary and SecondarySchool Students: 2002-03 (NCES 2005-010). U.S. Department of Education. Washington, DC:National Center for Education Statistics. http://nces.ed.gov/pubs2005/2005010.pdf.

[45] You, J. W. , \& Kang, M. (2014) The role of academic emotions in the relationship between perceived academic control and self-regulated learning in online learning. Computers \& Education, 77, 125-133.

[46] Yusuf, B.N.2020. Are we prepared enough? A case study of challenges in online learning in a private higher learning institution during the Covid-19 outbreaks. Adv. Soc. Sci. Res. J. 2020, 7, 205-212. 